\title{
Temperature Effects on Rheological Properties of Fresh Thickened Copper Tailings that Contain Cement
}

\author{
Yong Wang $\mathbb{D}^{1},{ }^{1,2}$ Aixiang Wu, ${ }^{1,3}$ Zhuen Ruan, ${ }^{1,3}$ Hongjiang Wang, ${ }^{3}$ Yiming Wang, ${ }^{3}$ \\ and Fei Jin ${ }^{1}$ \\ ${ }^{1}$ Key Laboratory of High-Efficient Mining and Safety of Metal Mines of Ministry of Education, University of Science and \\ Technology Beijing, Beijing 100083, China \\ ${ }^{2}$ State Key Laboratory of Coal Resources and Safe Mining, China University of Mining and Technology, Xuzhou 221116, China \\ ${ }^{3}$ School of Civil and Resource Engineering, University of Science and Technology Beijing, Beijing 100083, China
}

Correspondence should be addressed to Yong Wang; wangyong8551@126.com

Received 27 November 2017; Accepted 15 February 2018; Published 8 May 2018

Academic Editor: Francisco Javier Deive

Copyright (c) 2018 Yong Wang et al. This is an open access article distributed under the Creative Commons Attribution License, which permits unrestricted use, distribution, and reproduction in any medium, provided the original work is properly cited.

Cemented paste backfill (CPB) is an economic and environmental friendly technique applied in underground mining for supporting surrounding rock and replacing the pillar. However, little is known about the temperature effects on CPB in mines having a large temperature fluctuation. The main purpose of this research was to investigate the effect of temperature change on the rheological properties (e.g., shear stress and apparent viscosity) of CPB with copper mine tailings. Specifically, a series of rheological tests were conducted on $6 \mathrm{CPB}$ samples using a Brookfield $\mathrm{R} / \mathrm{S}+$ Rheometer under various temperatures $\left(2^{\circ} \mathrm{C}, 10^{\circ} \mathrm{C}\right.$, $20^{\circ} \mathrm{C}, 30^{\circ} \mathrm{C}, 40^{\circ} \mathrm{C}$, and $60^{\circ} \mathrm{C}$ ). Our results showed that both shear stress and apparent viscosity of these tailing samples increased with temperature rising from 2 to $60^{\circ} \mathrm{C}$. Likewise, temperature has a significant impact on the Bingham yield stress of thickened tailings. The yield stress decreased from $122 \mathrm{~Pa}\left(2^{\circ} \mathrm{C}\right)$ to $112 \mathrm{~Pa}\left(20^{\circ} \mathrm{C}\right)$ and then increased to $152 \mathrm{~Pa}\left(60^{\circ} \mathrm{C}\right)$. Moreover, the pipeline transport pressure drop of $\mathrm{CPB}$ at various temperatures was calculated, illustrating an obvious effect on the paste pipeline transport. Compared with $20^{\circ} \mathrm{C}$, the pressure drop under $2^{\circ} \mathrm{C}$ and $60^{\circ} \mathrm{C}$ increased by $11 \%$ and $22 \%$, respectively. The results of this study indicate that the temperature plays an essential role in determining rheological properties of $\mathrm{CPB}$ and its engineering application in mines particularly with naturally fluctuating temperatures.

\section{Introduction}

Cemented paste backfill (CPB) is an economic and environmental friendly technique applied in underground mining for supporting surrounding rock and replacing the pillar [1-3]. Over the years, the CPB technology has been widely adopted in the mining industry around the world [4-6]. CPB is usually composed of thickened or filtered tailings from concentrating mills, binding materials, and mixing water. The solid (tailings and binder) weight concentration of $\mathrm{CPB}$ generally ranges from 70 to $85 \%$ depending on the tailings fineness. The additional proportion of binder is commonly between 2 and 7\% of the whole paste weight. But it is reported that up to $10 \%$ binder is used for the improvement of CPB strength [7].
With the development of environmental technologies, one main challenge faced by $\mathrm{CPB}$ technology is the paste transport which is affected by the paste concentrations, solid compositions, stowing gradients, and temperature [8-10]. However, temperature as a key factor has been given less attention. Indeed, various temperatures of $\mathrm{CPB}$ are universal existence in mines since mines are located in different geographical and altitude positions. Other parameters can also influence the temperature of $\mathrm{CPB}$, such as mine depth and heat due to the binder hydration [3, 11]. When transported through the pipe network, the backfill increases the heat during the paths towards the production area [12]. All of these factors can lead to different temperatures once $\mathrm{CPB}$ is in the pipeline for transportation. 
However, studies on the effect of temperature on rheological properties of $\mathrm{CPB}$ are less frequently investigated [13-15]. Zhang et al. [16] investigated the rheological properties of fresh cement asphalt (CA) paste and discussed the influencing factors such as type of asphalt emulsion, temperature, and time. The result showed that high temperature led to an increase in the initial yield stress of the CA paste samples. Nehdi and Martini [17] studied the effects of the mixing time and temperature on the yield stress of cemented pastes incorporating various super plasticizers, where the yield stress was characterized by the oscillatory shear test. The result showed that the yield stress of cemented paste increases with the increase of temperature within the range of $22 \sim 45^{\circ} \mathrm{C}$. $\mathrm{Li}[18]$ analyzed the problems in $\mathrm{CPB}$ by a loop-pipe pumping experiment. He pointed out that temperature rise causes an increase of paste viscosity and pipeline transport resistance which is disadvantageous for the paste pumping process. The increase of temperature was mainly due to the fact of binder hydration and pipe inner surface friction. Crowder [19] mentioned that the variation in yield stress and viscosity with temperature was quite significant. Yet, there is no specific and systematic study on the paste rheological properties with temperature.

In China, most areas have four distinct seasons. Jiashi copper mine (copper grade greater than $1.176 \%$ ), located in the west of Xinjiang autonomous region of China, was commissioned in 2004. Due to surrounding rock crushing and wet deposition weathering, Jiashi was proposed to introduce $\mathrm{CPB}$ to control these problems. The experimental results indicated that the $\mathrm{CPB}$ strength should reach up to $4 \mathrm{MPa}$ and cement/tailings ratio should be about $1: 5$. With the mining depth increasing in the future, the paste transport distance will be increased as well. In addition, the highest and lowest temperature in this mine can be reached to $45^{\circ} \mathrm{C}$ and $-22^{\circ} \mathrm{C}$, respectively. Considering the abovementioned facts, the main objective of this research was to experimentally study the effect of temperature on apparent viscosity, shear stress, yield stress, and pipeline transport of paste.

\section{Materials and Methods}

2.1. Materials Used. Total tailings, binder, and tap water of the same mix proportion were used to prepare the paste samples under different temperature conditions.

2.1.1. Tailings. Unclassified tailings samples were collected from Jiashi copper mine in Xinjiang autonomous region, China. The ore body and surrounding rock of this copper mine are subject to significant argillization, turning into a clay-like material when in contact with water due to the fact of sandstone rock soil type. This characteristic is harmful to the $\mathrm{CPB}$ transportation, and the temperature has a more sensitive effect on its rheology parameter. Therefore, the consideration of the temperature effect became more important for this type tailings CPB transportation assessment. The particle size distribution (PSD) of tailing samples was measured with Malvern Laser

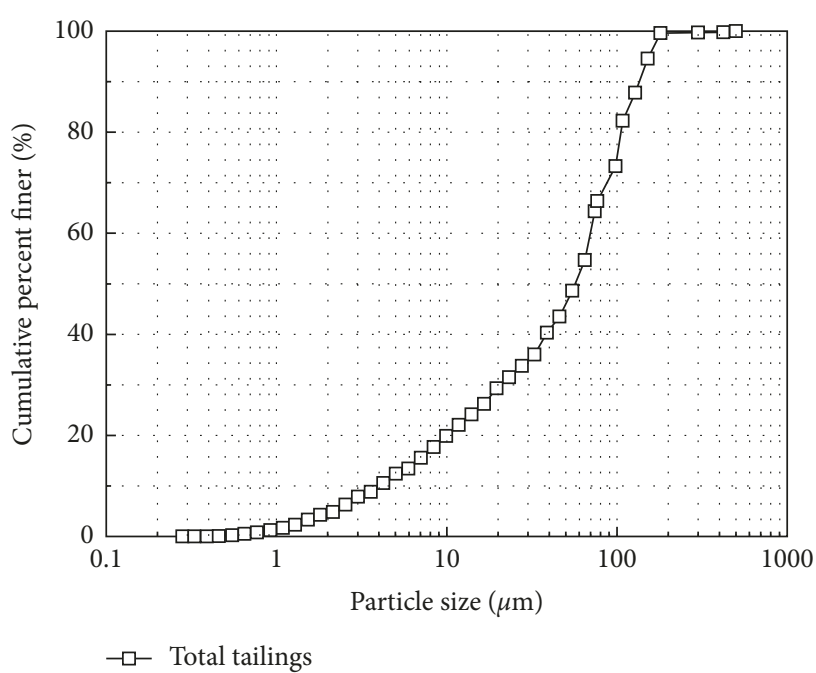

Figure 1: Particle size distribution of the tailings used in the experiments.

TABle 1: Physicochemical characterization of the tailings.

\begin{tabular}{|c|c|}
\hline Characteristics & Content $\%$ \\
\hline \multicolumn{2}{|l|}{ Chemical composition } \\
\hline $\mathrm{SiO}_{2}$ & 64.00 \\
\hline $\mathrm{Al}_{2} \mathrm{O}_{3}$ & 6.20 \\
\hline S & 0.39 \\
\hline $\mathrm{MgO}$ & 1.40 \\
\hline $\mathrm{CaO}$ & 9.20 \\
\hline $\mathrm{K}_{2} \mathrm{O}$ & Not detected \\
\hline $\mathrm{Na}_{2} \mathrm{O}$ & Not detected \\
\hline Loss-on-ignition (LOI) & 17.00 \\
\hline Total & 98.00 \\
\hline \multicolumn{2}{|l|}{ Physical properties } \\
\hline Solid density $\left(\mathrm{kg} \cdot \mathrm{m}^{-3}\right)$ & 2660.00 \\
\hline Tightly packed bulk density $\left(\mathrm{kg} \cdot \mathrm{m}^{-3}\right)$ & 1600.00 \\
\hline Porosity $(\%)$ & 39.70 \\
\hline Specific surface area $\left(\mathrm{m}^{2} \cdot \mathrm{cm}^{-3}\right)$ & 0.61 \\
\hline
\end{tabular}

Mastersizer 2000 (Malvern, UK), which can measure particle size in the range of 0.02 to $2000 \mu \mathrm{m}$ with an accuracy of $\pm 1 \%$. As shown in Figure 1, particles which are smaller than $74 \mu \mathrm{m}$ account for $64.32 \mathrm{wt}$. \% of the tailings, and ones smaller than $20 \mu \mathrm{m}$ account for $29.8 \mathrm{wt}$. \%.

Table 1 shows the physicochemical properties of the tailings. On the basis of the result of specific gravity [20], the true solid density of the tailings was calculated by (1). With the pycnometer method as per standard ASTM D854, the specific gravity $\left(G_{s}\right)$ of the tailings was obtained:

$$
\rho_{\mathrm{s}}=G_{\mathrm{s}} \rho_{\mathrm{w}},
$$

where $\rho_{\mathrm{s}}$ is true solid density of dry tailing, $G_{\mathrm{s}}$ is specific gravity of dry tailing, and $\rho_{\mathrm{w}}$ is the water density at $20^{\circ} \mathrm{C}$. It should be noted that $G_{s}$ is a dimensionless parameter.

The tailings bulk density was measured on the basis of standard GB/T 14684-2001 (6.14.2.3). A known mass of dry tailings was filled into a measuring cylinder, and then, a rubber was covered on the flat surface of the cylinder. The cylinder was tapped until the volume of tailings became 
TABLE 2: Composition of different paste samples used in this study.

\begin{tabular}{|c|c|c|c|c|c|c|c|}
\hline \multirow{2}{*}{ Mixture name } & \multirow{2}{*}{ Temperature $\left({ }^{\circ} \mathrm{C}\right)$} & \multicolumn{2}{|c|}{ Tailings } & \multicolumn{2}{|c|}{ Binder } & \multicolumn{2}{|c|}{ Water } \\
\hline & & Type & $\mathrm{t} / \mathrm{c}$ ratio & Type & wt. $\%$ & Type & $\mathrm{w} / \mathrm{c}$ ratio \\
\hline CPB-A & 2 & SST & 5 & PCI & 12.33 & Tap water & 2.11 \\
\hline CPB-B & 10 & SST & 5 & PCI & 12.33 & Tap water & 2.11 \\
\hline CPB-C & 20 & SST & 5 & PCI & 12.33 & Tap water & 2.11 \\
\hline CPB-D & 30 & SST & 5 & PCI & 12.33 & Tap water & 2.11 \\
\hline CPB-E & 40 & SST & 5 & PCI & 12.33 & Tap water & 2.11 \\
\hline $\mathrm{CPB}-\mathrm{F}$ & 60 & SST & 5 & PCI & 12.33 & Tap water & 2.11 \\
\hline
\end{tabular}

Note: SST denotes sandstone sulphide tailings, and PCI denotes Portland cement type I.

constant. The bulk density of the tailings was the ratio of the tailings mass to its volume in the cylinder [21]. The dry tailings porosity $(n)$ can be estimated as follows:

$$
n=\left(1-\frac{\rho}{\rho_{s}}\right) \times 100 \%,
$$

where $n$ is the porosity and $\rho$ is the bulk density.

To ensure reproducibility of the results, the true solid density and bulk density of three tailing samples were analyzed in triplicate, and an average value of these three measurements are given in the Table 1. Prior to characterization of these physical properties, the tailing samples were dried in an oven at $105 \pm 5^{\circ} \mathrm{C}$ for 24 hours as per the standard ASTM D2216.

The mineralogical analysis was performed on micronized tailings by X-ray diffraction (XRD). The specimen pieces were ground as powders to ensure all particles size were finer than $80 \mu \mathrm{m}$. The apparatus used for XRD analysis was equipment that with an incident radiation of $\mathrm{Cu} \mathrm{K \alpha}$ and an acceleration voltage of $35 \mathrm{kV}$ and $30 \mathrm{~mA}$. Data collection was done at angle $2 \theta$ increasing from $10^{\circ}$ to $80^{\circ}$. The step size of this analysis is $0.005^{\circ}$, and a counting time of each step is $0.5 \mathrm{~s}$. The main chemical composition of the tailing sample is $\mathrm{SiO}_{2}$ accounting for $64 \%$ in content.

2.1.2. Binder. The binding agent used for paste production was Portland cement type I (PCI) from Xinjiang Tianshan Cement Co., Ltd. in China.

2.1.3. Mixing Water. Tap water was used to prepare all the paste samples. Constant water amount (i.e., $221 \mathrm{~g}$ ) was ensured to obtain the same paste consistency.

2.2. Mixing Procedure and Mix Proportions. Since slurry temperature was below $2^{\circ} \mathrm{C}$, it starts to freeze, thus losing rheological properties. Therefore, the temperatures investigated in this study were $2,10,20,30,40$, and $60^{\circ} \mathrm{C}$, ranging from the lowest flowable paste temperature to the highest possible temperature in pipeline.

A total of 6 CPB samples with a constant binder content of $12.3 \%$, water/cement $(\mathrm{w} / \mathrm{c})$ ratio of 2.11 , tailings/cement $(\mathrm{t} / \mathrm{c})$ ratio of 5 , and the same tailings type were prepared. Each paste sample was prepared in a $500 \mathrm{~mL}$ beaker. Total weight of each sample was $850 \mathrm{~g}$ (524.2 g tailings, $104.8 \mathrm{~g}$ cement, and $221 \mathrm{~g}$ water). The ratio of solid mass (tailings mass plus cement

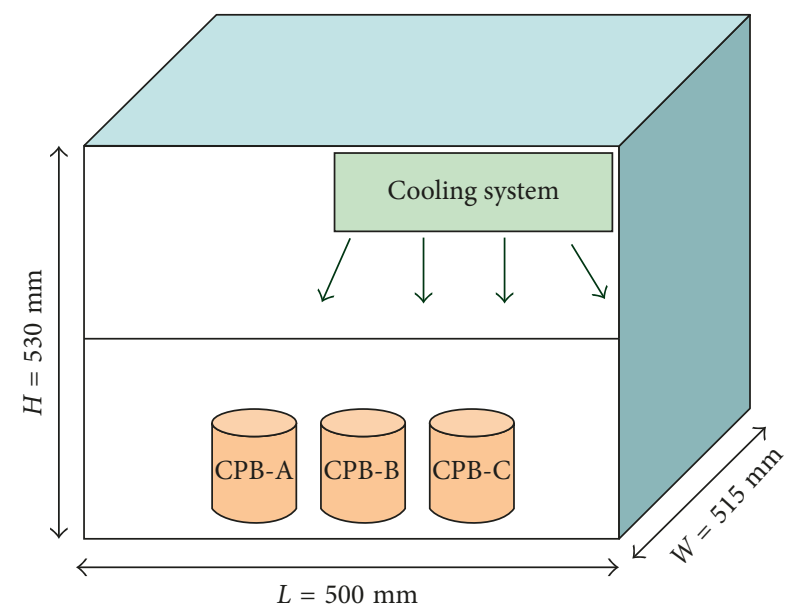

FIgURE 2: Schematic diagram of the refrigerator for the samples CPB-A, CPB-B, and CPB-C.

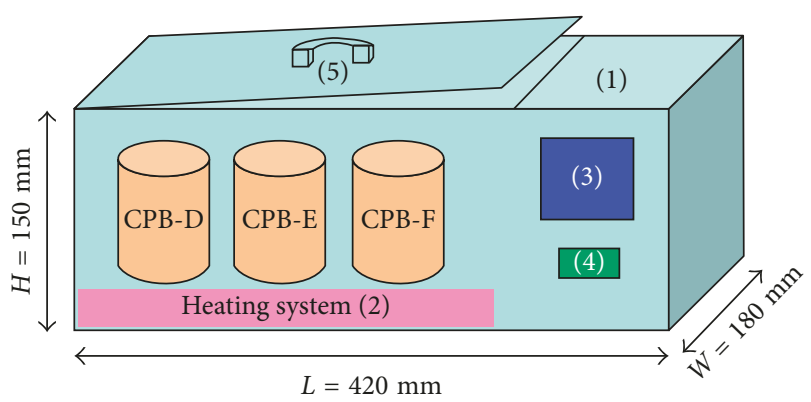

FIgURE 3: Schematic diagram for the temperature water bath samples CPB-D, CPB-E, and CPB-F. (1) Reactor of stainless steel; (2) heating system; (3) digital temperature display and microcomputer control; (4) power switch; (5) cover.

mass) to total mass (solid mass plus liquid mass) was $74 \%$. Composition of different paste samples is given in Table 2. It should be noted that the only difference among these samples was temperature. The tailing materials, binder, and water were mixed and homogenized for about $5 \mathrm{~min}$ to produce the desired paste mixtures. The six samples were named CPB-A, CPB-B, CPB-C, CPB-D, CPB-E, and CPB-F, respectively.

2.3. Temperature Control. Two schematic representations of the experimental setup developed to achieve the desired temperatures are illustrated in Figures 2 and 3. One 


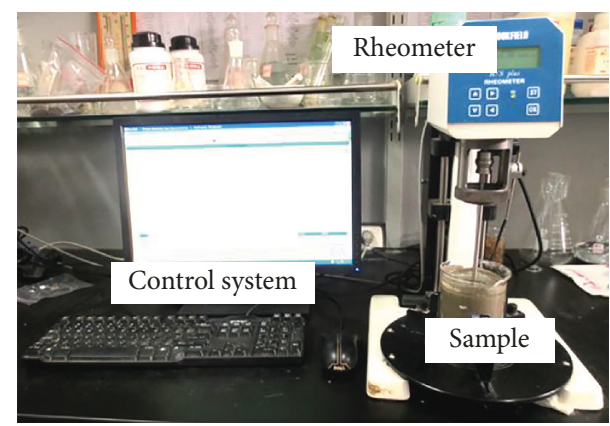

FIgURE 4: The picture of the Brookfield R/S+ Rheometer.

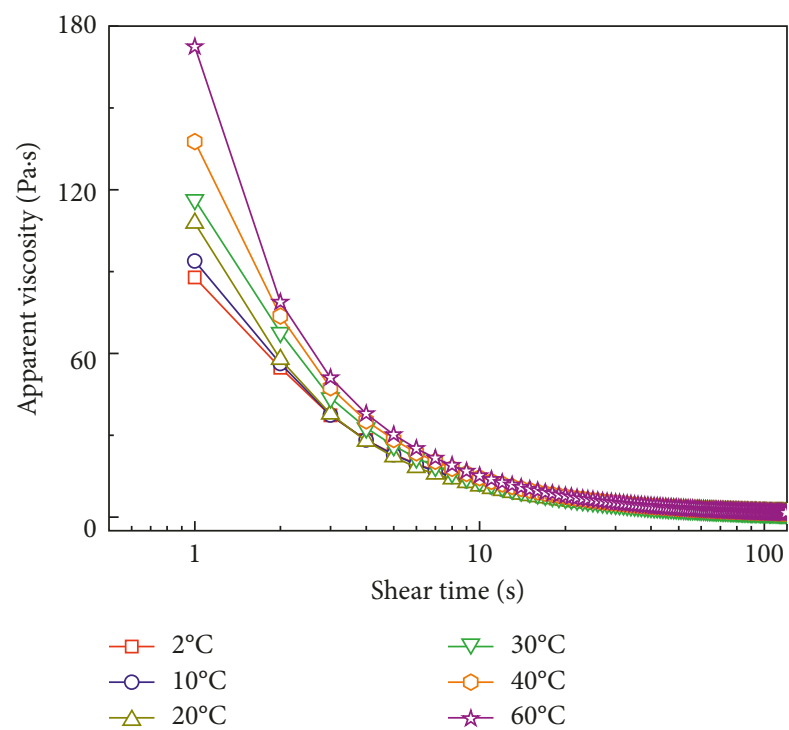

FIgURE 5: Apparent viscosity change as a function of shear time under different temperature conditions.

experimental setup was a small refrigerator with the lowest temperature of $-4^{\circ} \mathrm{C}$. Since the experimental ambient temperature was about $28^{\circ} \mathrm{C}$, the temperature for the samples CPB-A, CPB-B, and CPB-C needed to be controlled in the refrigerator. $\mathrm{CPB}-\mathrm{A}, \mathrm{CPB}-\mathrm{B}$, and $\mathrm{CPB}-\mathrm{C}$ were cooled at 2, 10, and $20^{\circ} \mathrm{C}$, respectively. The other experimental setup was kept in a constant temperature water bath [22-24]. The experimental setup consists of an electronic unit controlling the water temperature. The heat is transferred to the paste samples via water. The water bath temperature was controlled with a precision of $0.1^{\circ} \mathrm{C}$. It was connected to a temperature sensor that continually measures the temperature in the water bath and automatically sends the data to the controller (3). The temperature control range is from $+5^{\circ} \mathrm{C}$ to $+99^{\circ} \mathrm{C}$ with a fluctuation of $\pm 0.5^{\circ} \mathrm{C}$. Temperature control for CPB-D, CPB-E, and $\mathrm{CPB}-\mathrm{F}$ was achieved in this water bath.

2.4. Testing Methods. For evaluating the rheological performance of the prepared paste samples, a Brookfield R/S+ Rheometer was employed to test the shear stress and apparent viscosity at various temperatures. The Brookfield $\mathrm{R} / \mathrm{S}+\mathrm{Rheometer}$ is given in Figure 4 . The sample holders for rheological testing were cylindrical glass beakers with

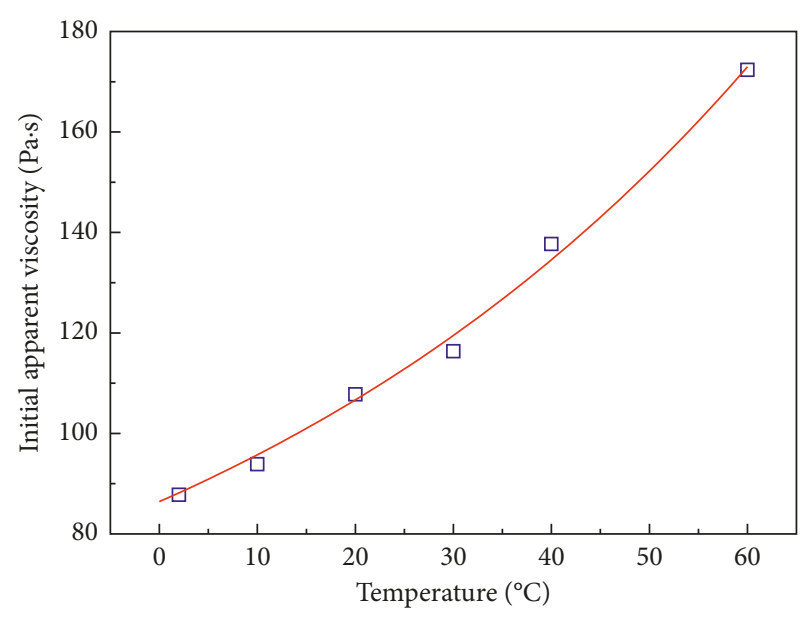

FIGURE 6: Effect of temperature on initial apparent viscosity (IAV) (the shear time was set at $1 \mathrm{~s}$ ).

a diameter of $75 \mathrm{~mm}$ and a height of $115 \mathrm{~mm}$. The height of the thickened tailings was about $100 \mathrm{~mm}$ to ensure immerse of the mixing rotor of the Brookfield R/S+ Rheometer into the prepared tailing samples. The samples were tamped 18 times using a glass rod to remove air bubbles and level the thickened tailings. After fixing the beaker, the test mode was then set on the controlled shear rate (CSR), and the shear rate $\left(\mathrm{s}^{-1}\right)$ and shear time (s) were set as $1 \mathrm{~s}^{-1}$ to $120 \mathrm{~s}^{-1}$ and $120 \mathrm{~s}$, respectively [25]. All measurements were in duplicate. Students' $t$-test was done on the two batch results to ensure the test repeatability. Finally, the average of the two test results was adopted for this study.

\section{Results and Discussion}

3.1. Effect of Temperature on Shear Stress and Apparent Viscosity. Figure 5 shows the coupled effects of shear time and temperature on apparent viscosity. With an increase of shear time, the structure of the paste was rapidly destroyed. Apparent viscosity decreased quickly within 10 seconds and was kept relatively stable. The apparent viscosity increased as a function of temperature with the same shear time. Figure 6 illustrates the effect of temperature on initial apparent viscosity, IAV. The regression equation of IAV as the function of temperature can be obtained:

$$
y=32.8+53.6 \exp \left(\frac{x}{62.5}\right)
$$

where $y$ is the initial apparent viscosity (Pa.s), and $x$ is the temperature $\left({ }^{\circ} \mathrm{C}\right)$. According to (3), the IAV exponentially increases with the increasing temperature.

3.2. Effect of Temperature on Shear Stress. Figure 7 indicates the shear stress change under different paste temperatures. From Figure 7, the shear rate and temperature significantly affect the paste shear stress. The slurry shear stress increased with the rise of temperature at low shear rate (i.e., $<2 \mathrm{~s}^{-1}$ ). Note that it is the relatively higher paste concentration brings a sudden rise when the rheometer starts. When the shear rate is above $2 \mathrm{~s}^{-1}$, the shear stress decreased and then 


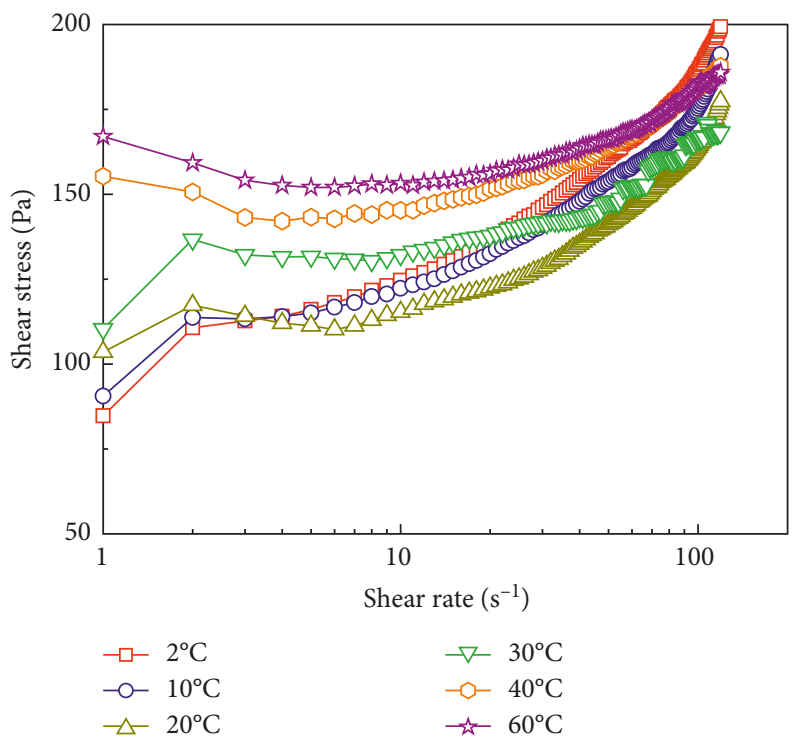

FiguRE 7: Effect of shear rate on shear stress of different paste temperatures.

TABLe 3: The fitting parameters for different samples based on the Bingham model.

\begin{tabular}{lccc}
\hline Mixture name & Temperature $\left({ }^{\circ} \mathrm{C}\right)$ & Bingham yield stress $(\mathrm{Pa})$ & Correlation coefficient $\left(R^{2}\right)$ \\
\hline CPB-A & 2 & 122.1 & 0.9487 \\
CPB-B & 10 & 119.9 & 0.9561 \\
CPB-C & 20 & 112.2 & 0.9903 \\
CPB-D & 30 & 129.8 & 0.9593 \\
CPB-E & 40 & 142.6 & 0.9237 \\
CPB-F & 60 & 151.5 & 0.9721 \\
\hline
\end{tabular}

increased gradually with the growth of the shear rate at the early stage $\left(<10 \mathrm{~s}^{-1}\right)$. It should be noted that the significance values of students' $t$-test for the duplicate tests are $0.72,0.76$, $0.93,0.89,0.88$, and 0.86 at the temperature $2^{\circ} \mathrm{C}, 10^{\circ} \mathrm{C}, 20^{\circ} \mathrm{C}$, $30^{\circ} \mathrm{C}, 40^{\circ} \mathrm{C}$, and $60^{\circ} \mathrm{C}$, respectively. These significance values are much larger than 0.05 , which indicates that the duplicate measurements have no significant difference.

At higher temperature, the change in the amplitude of $\mathrm{CPB}$ shear stress is smaller within the tested shear rate range. At the lower temperature of 2 to $30^{\circ} \mathrm{C}$, smaller initial shear stress (ISS) was observed. However, the shear stress increased rapidly when the shear rate was increased to $2 \mathrm{~s}^{-1}$. By comparison, the ISS at the temperature of $40^{\circ} \mathrm{C}$ and $60^{\circ} \mathrm{C}$ is higher than the low temperature, and the shear stress comes down first and then goes up with the increase of shear rate.

According to the shear stress profile, the temperature range of the slurry transport is divided into three areas: low temperature range $\left(2-20^{\circ} \mathrm{C}\right)$, medium temperature range $\left(20-40^{\circ} \mathrm{C}\right)$, and high temperature range $\left(40-60^{\circ} \mathrm{C}\right)$. The change of shear stress is the greatest with the increasing shear rate at the low temperature area; at medium temperature, the area is second; and at high temperature, the area is smallest.

\subsection{Bingham Model and Temperature Analysis}

3.3.1. Bingham Model. The Bingham and Herschel-Bulkley models are commonly applied in paste rheology. When the critical stress at which the cement paste transforms from elastic to viscous state, the Bingham model is suitable for the paste research in this study [26]. The Bingham model is as follows:

$$
\tau=\tau_{0}+\mu_{\mathrm{B}} \gamma
$$

where $\tau$ is the shear stress $(\mathrm{Pa}), \tau_{0}$ is the yield stress $(\mathrm{Pa}), \mu_{\mathrm{B}}$ is the plastic viscosity $(\mathrm{Pa} \cdot \mathrm{s})$, and $\gamma$ is the shear rate $\left(\mathrm{s}^{-1}\right)$. The parameters obtained from the fitting equation according to the Bingham model and test results are given in Table 3 . The correlation coefficient $\left(R^{2}\right)$ means a measure of the correlation between a dependent variable and a set of independent variables (two or more). As the correlation coefficient is more nearly to 1 , it indicates that the dependent variable and independent variables are more relevant. These coefficients were calculated by the regression of test results using the Bingham model. The lowest correlation coefficient $\left(R^{2}\right)$ result by the Bingham model for different solid concentration levels is 0.9237, indicating that the Bingham model is suitable to describe the flow curves of these CPB samples.

3.3.2. Effect of Temperature on Regression Yield Stress. The aim of this section was to explain the mechanism how temperature affects the paste yield stress. According to Table 3, the relationship between Bingham yield stress and paste temperature is plotted in Figure 8. 


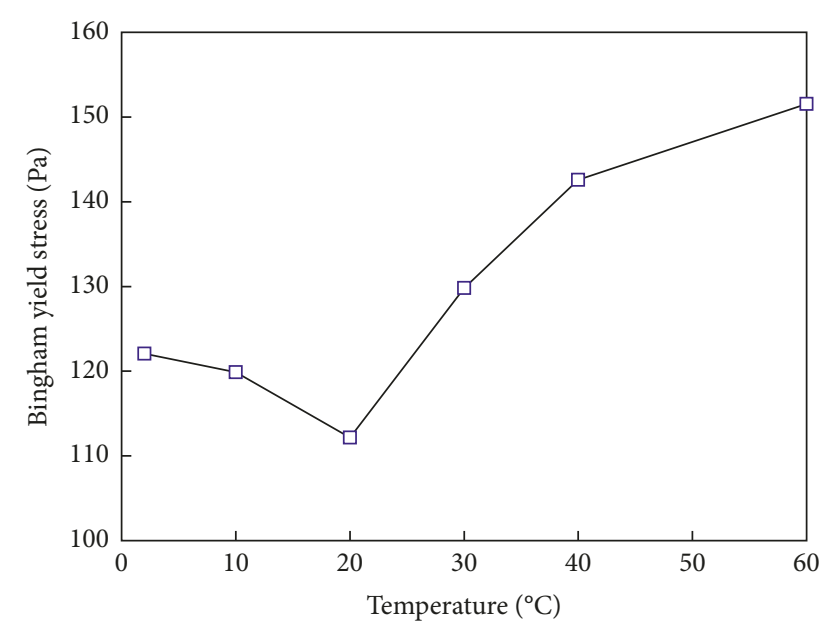

Figure 8: Effect of temperature on paste Bingham yield stress.

As shown in Figure 8, the paste yield stress rises along with temperature after an initial decrease until $20^{\circ} \mathrm{C}$. They can be generalized in the following three aspects: (1) The paste has thaw at the temperature of $2^{\circ} \mathrm{C}$, which leads to high yield stress. As the temperature increases, the flow performance of slurry becomes better. Hence, the yield stress decreases gradually until it reaches $20^{\circ} \mathrm{C}$. (2) When the temperature of paste increases, the volume expansion coefficient of slurry exponentially increases $\left(0.63\right.$ to $\left.5.11 \times 10^{-4} \mathrm{~K}^{-1}\right)$ [27]. This led to the tailings being pressed, and the interaction force of the particles increasing, which causes the yield stress to rise after $20^{\circ} \mathrm{C}$. (3) The cement was added in the experimental process. The hydration reaction should be considered in this study because slight hydration reaction occurred during the sample preparation and curing. The increase of the hydration reaction rate became more pronounced at higher temperature, reflecting the acceleration of hydration reactions of cement at high temperature [28].

3.3.3. Effect of Temperature on Pipeline Transport of CPB. Pipeline transport is a key technology of $\mathrm{CPB}$, and the pressure drop reflects the paste flowing capacity. Pressure drop of the pipeline transport refers to the paste pressure difference per unit flowing length. Hence, in order to evaluate the effect of temperature on the $\mathrm{CPB}$ pipeline transport, the pressure drop at different temperatures needs to be calculated. The following equation is an expression of pressure drop based on the Bingham model:

$$
i_{\mathrm{m}}=\frac{16}{3 D} \tau_{0}+\frac{32 U}{D^{2}} \mu_{\mathrm{B}}
$$

where $i_{\mathrm{m}}$ is the pressure $\operatorname{drop}\left(\mathrm{Pa} \cdot \mathrm{m}^{-1}\right), U$ is the flow velocity $(\mathrm{m} / \mathrm{s})$, and $D$ is the pipe diameter $(\mathrm{m})$. According to previous backfilling experiences, the parameters of the paste pipeline transport are assumed as follows: pipe diameter is $150 \mathrm{~mm}$, and paste flow velocity is $1 \mathrm{~m} \cdot \mathrm{s}^{-1}$. The parameters in Table 3 , together with the pipe diameter and flow velocity, were plugged into (5). The calculated pressure drop of paste and ascensional range at different temperatures are given in the Table 4.
Table 4: Pressure drop of the pipeline transport at different temperatures.

\begin{tabular}{lcccccc}
\hline Temperature $\left({ }^{\circ} \mathrm{C}\right)$ & 0 & 10 & 20 & 30 & 40 & 60 \\
\hline Pressure drop $\left(\mathrm{Pa} \cdot \mathrm{m}^{-1}\right)$ & 5293 & 5096 & 4749 & 5129 & 5632 & 5804 \\
Ascensional range $(\mathrm{Ar}) \%$ & 11.50 & 7.31 & 0.00 & 8.00 & 18.60 & 22.20 \\
\hline
\end{tabular}

Note: $\operatorname{Ar}=\left(i_{\text {int }}-i_{\text {int }}^{\prime}\right) / i_{\text {int }}^{\prime}$, where $i_{\text {int }}$ is the pressure drop of the temperature $(\mathrm{Pa} / \mathrm{m})$, and $i_{\text {int }}^{\prime}$ is the lowest pressure drop of all the temperatures $\left(\mathrm{Pa} \cdot \mathrm{m}^{-1}\right)$.

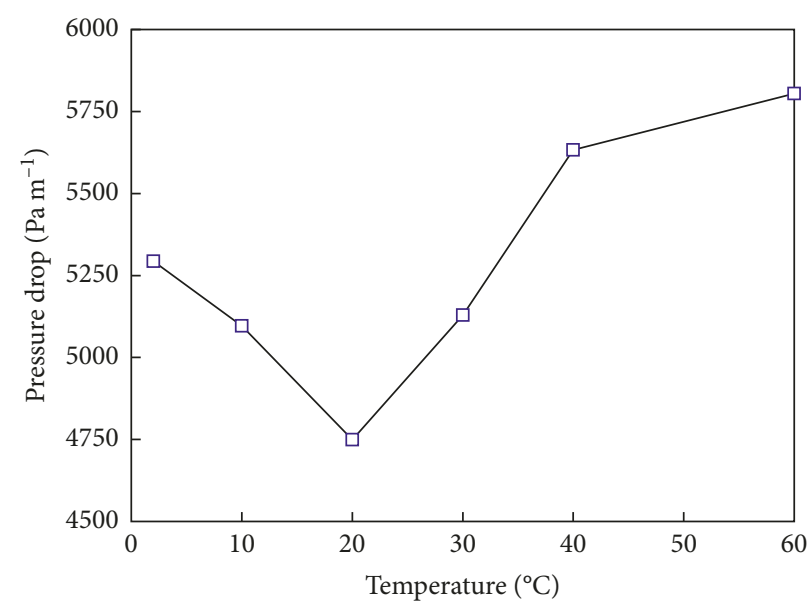

FIGURE 9: Effect of temperature on the pressure drop of paste flow.

Figure 9 illustrates the effect of temperature on pressure drop, demonstrating the transport difficulty of paste at different temperatures. From Figure 9, it is obvious that the temperature has an impact on the paste pipeline transport. The paste pressure drop at $20^{\circ} \mathrm{C}$ decreased by $11.2 \%$ and $22.2 \%$ compared with $2^{\circ} \mathrm{C}$ and $60^{\circ} \mathrm{C}$, respectively. High temperature area is more adverse than low temperature range to paste transport. Hence, the temperature of paste in the pipeline should be controlled between 10 and $30^{\circ} \mathrm{C}$ when backfilling because the pressure drop at this temperature range is relatively lower. For example, when the temperature is over $40^{\circ} \mathrm{C}$, the Ar was $18.6 \%$, which was greater than that at $20^{\circ} \mathrm{C}$. This temperature should be considered as a critical temperature for the paste transport.

\section{Conclusions}

This study attempted to advance our understanding on the influence of temperature on the rheological properties (e.g., shear stress and apparent viscosity) and pipeline transport of CPB through a series of tests. The main conclusions derived from this study are summarized as follows:

(1) The temperature played an essential role in determining rheological properties of $\mathrm{CPB}$. Elevated temperature led to an increase of the paste apparent viscosity for many reasons (e.g., hydration reaction of binder and tailings) that in turn caused the shear stress to increase. Further, within a certain temperature, the shear stress increased with the rising of shear rate.

(2) The temperature has to be brought into consideration to account for the change of paste Bingham 
yield stress and pressure drop of the paste pipeline transport. The yield stress decreased from $122.1 \mathrm{~Pa}$ to 112.2 $\mathrm{Pa}$ while the paste temperature rose from $2^{\circ} \mathrm{C}$ to $20^{\circ} \mathrm{C}$. Then, the yield stress increased from $112.2 \mathrm{~Pa}$ to $151.6 \mathrm{~Pa}$ while the paste temperature rose from $20^{\circ} \mathrm{C}$ to $60^{\circ} \mathrm{C}$. Furthermore, the pressure drop of the paste pipeline transport with different temperatures was calculated. The pressure drop at $20^{\circ} \mathrm{C}$ decreased by $11.2 \%$ and $22.2 \%$ compared with that of $2^{\circ} \mathrm{C}$ and $60^{\circ} \mathrm{C}$, respectively.

(3) The most appropriate temperature range for the paste transport was determined to be from 10 to $30^{\circ} \mathrm{C}$. Temperatures higher than $40^{\circ} \mathrm{C}$ should be considered disadvantageous to paste transport. Therefore, it is suggested in mine backfill operations that the effect of temperature on the paste rheological properties should be taken into account in the $\mathrm{CPB}$ pipeline transport. If the paste temperature is too low or too high, temperature control measures (e.g., reducing concentration, improving pumping pressure, and cooling pipeline artificially) should be taken in order to make the paste transport easy and reliable.

Despite the results obtained in this study, further studies are necessary to provide a better understanding of the effect of temperature on the paste transport. The following topics are recommended for further work: (i) effect of temperature on microscopic structure change of fresh paste, (ii) industrial experiments to testify the effect of temperature on the pipeline transport, and (iii) a numerical model allowing the prediction of the rheological properties with the composition, concentration, pipe diameter, and flow velocity, subjected to different temperatures.

\section{Conflicts of Interest}

The authors declare that there are no conflicts of interest regarding the publication of this paper.

\section{Acknowledgments}

This research was funded by the State Key Research Development Program of China (no. 2017YFC0602903), the Research Fund of the State Key Laboratory of Coal Resources and Safe Mining, CUMT (no. SKLCRSM18KF006), the China Postdoctoral Science Foundation (no. 2017M620622), the Fundamental Research Funds for the Central Universities (no. FRF-TP-17-024A1), and the National Natural Science Foundation of China (nos. 51574013 and 51674012).

\section{References}

[1] F. W. Brackebusch, "Basics of paste backfill systems," International Journal of Rock Mechanics \& Mining Science \& Geomechanics Abstracts, vol. 32, no. 3, p. 122A, 1994.

[2] M. Fall, M. Benzaazoua, and E. G. Saa, "Mix proportioning of underground cemented tailings backfill," Tunnelling and Underground Space Technology, vol. 23, no. 1, pp. 80-90, 2008.

[3] Y. Wang, M. Fall, and A. Wu, "Initial temperaturedependence of strength development and self-desiccation in cemented paste backfill that contains sodium silicate," Cement and Concrete Composites, vol. 67, pp. 101-110, 2016.

[4] T. Belem, A. Fourie, and M. Fahey, "Time-dependent failure criterion for cemented paste backfills," in Proceedings of the 13th International Seminar on Paste and Thickened Tailings, pp. 147-162, Toronto, Canada, May 2010.

[5] M. Fall and O. Nasir, "Predicting the temperature and strength development within cemented paste backfill structures," in Proceedings of the 13th International Seminar on Paste and Thickened Tailings, pp. 147-162, Toronto, Canada, May 2010.

[6] M. Grabinsky, "In situ monitoring for ground truthing paste backfill designs," in Proceedings of the 13th International Seminar on Paste and Thickened Tailings, pp. 147-162, Toronto, Canada, May 2010.

[7] T. J. Williams, D. K. Denton, M. K. Larson, R. L. Rains, J. B. Seymour, and D. R. Tesarik, "Geomechanics of reinforced cemented backfill in an underground stope at the Lucky Friday mine," Tech. Rep. of Investigations. 9655, U.S. Department of Health and Human Services, Washington, DC, USA, 2001.

[8] S. Luo, Z. Wei, R. Spinney, Z. Yang, L. Chai, and R. Xiao, “A novel model to predict gas-phase hydroxyl radical oxidation kinetics of polychlorinated compounds," Chemosphere, vol. 172, pp. 333-340, 2017.

[9] S. Luo, Z. Wei, D. D. Dionysiou et al., "Mechanistic insight into reactivity of sulfate radical with aromatic contaminants through single-electron transfer pathway," Chemical Engineering Journal, vol. 327, pp. 1056-1065, 2017.

[10] T. Ye, Z. Wei, R. Spinney et al., "Quantitative structureactivity relationship for the apparent rate constants of aromatic contaminants oxidized by ferrate (VI)," Chemical Engineering Journal, vol. 317, pp. 258-266, 2017.

[11] A. Wu, Y. Wang, B. Zhou, and J. Shen, "Effect of initial backfill temperature on the deformation behavior of early age cemented paste backfill that contains sodium silicate," Advances in Materials Science and Engineering, vol. 2016, Article ID 8481090, 10 pages, 2016.

[12] C. Rawlins and H. Phillips, "Reduction of mine heat loads," in Proceedings of the 7th International Mine Ventilation Congress, pp. 381-389, Cracow, Poland, June 2001.

[13] Z. Wei, R. Spinney, R. Ke, Z. Yang, and R. Xiao, "Effect of pH on the sonochemical degradation of organic pollutants," Environmental Chemistry Letters, vol. 14, no. 2, pp. 163-182, 2016.

[14] Z. Yang, R. Su, S. Luo et al., "Comparison of the reactivity of ibuprofen with sulfate and hydroxyl radicals: an experimental and theoretical study," Science of the Total Environment, vol. 590-591, pp. 751-760, 2017.

[15] T. Ye, Z. Wei, R. Spinney et al., "Chemical structure-based predictive model for the oxidation of trace organic contaminants by sulfate radical," Water Research, vol. 116, pp. 106-115, 2017.

[16] Y. Zhang, X. Kong, S. Hou, Y. Liu, and S. Han, "Study on the rheological properties of fresh cement asphalt paste," Construction and Building Materials, vol. 27, no. 1, pp. 534-544, 2012.

[17] M. Nehdi and S. A. Martini, "Estimating time and temperature dependent yield stress of cement paste using oscillatory rheology and genetic algorithms," Cement and Concrete Research, vol. 39, no. 11, pp. 1007-1016, 2009.

[18] G. Li, "The influence of different constitution tailing paste on pumping looping pipe experiment," Gold, vol. 28, pp. 33-36, 2007.

[19] J. J. Crowder, Deposition, Consolidation, and Strength of a Non-Plastic Tailings Paste for Surface Disposal, University of Toronto, Toronto, ON, Canada, 2004. 
[20] N. Yesiller, J. L. Hanson, J. T. Cox, and D. E. Noce, "Determination of specific gravity of municipal solid waste," Waste Management, vol. 34, no. 5, pp. 848-858, 2014.

[21] E. C. Abdullah and D. Geldart, "The use of bulk density measurements as flowability indicators," Powder Technology, vol. 102, no. 2, pp. 151-165, 1999.

[22] S. Luo, Z. Wei, R. Spinney et al., "UV direct photolysis of sulfamethoxazole and ibuprofen: an experimental and modelling study," Journal of Hazardous Materials, vol. 343, pp. 132-139, 2018.

[23] M. Cai, J. Hu, G. Lian et al., "Synergetic pretreatment of waste activated sludge by hydrodynamic cavitation combined with Fenton reaction for enhanced dewatering," Ultrasonics Sonochemistry, vol. 42, pp. 609-618, 2018.

[24] R. Xiao, L. Gao, Z. Wei et al., "Mechanistic insight into degradation of endocrine disrupting chemical by hydroxyl radical: an experimental and theoretical approach," Environmental Pollution, vol. 231, pp. 1446-1452, 2017.

[25] A. Wu, Y. Wang, and H. Wang, "Estimation model for yield stress of fresh uncemented thickened tailings: coupled effects of true solid density, bulk density, and solid concentration," International Journal of Mineral Processing, vol. 143, pp. 117-124, 2015.

[26] A. Wu, Y. Wang, H. Wang, S. Yin, and X. Miao, "Coupled effects of cement type and water quality on the properties of cemented paste backfill," International Journal of Mineral Processing, vol. 143, pp. 65-71, 2015.

[27] J. Yan, X. Yu, and Y. Wang, Thermodynamic Property Tables and Diagram for Water and Steam, Higher Education Press, Beijing, China, 2nd edition, 2004.

[28] S. Al-Martini and M. Nehdi, "Effect of chemical admixtures on rheology of cement paste at high temperature," Journal of ASTM International, vol. 4, pp. 11-17, 2007. 

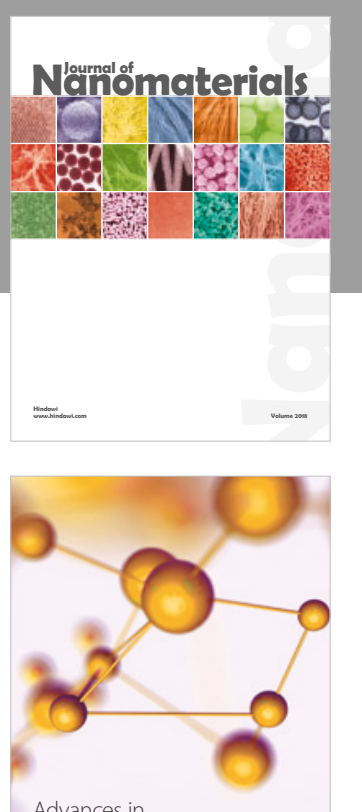

Physical Chemistry
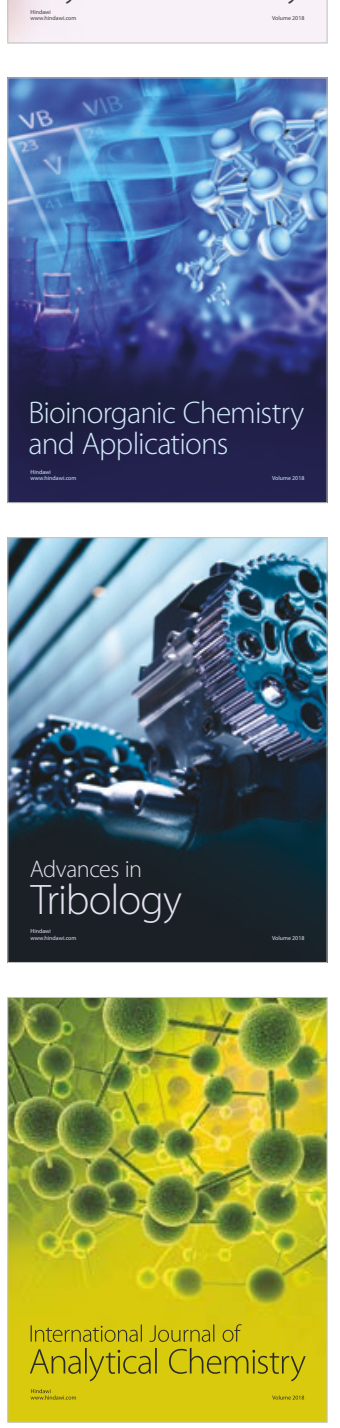

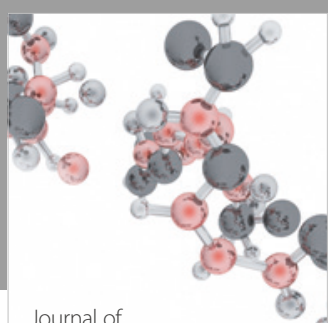

Analytical Methods

in Chemistry

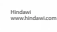

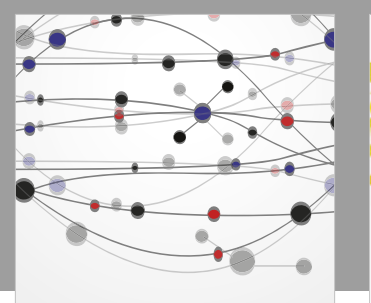

The Scientific World Journal

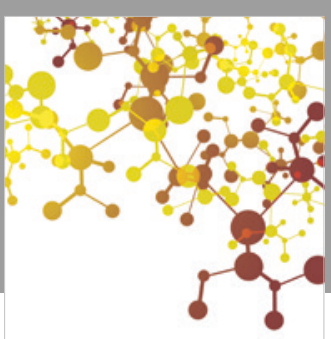

Journal of

Applied Chemistry
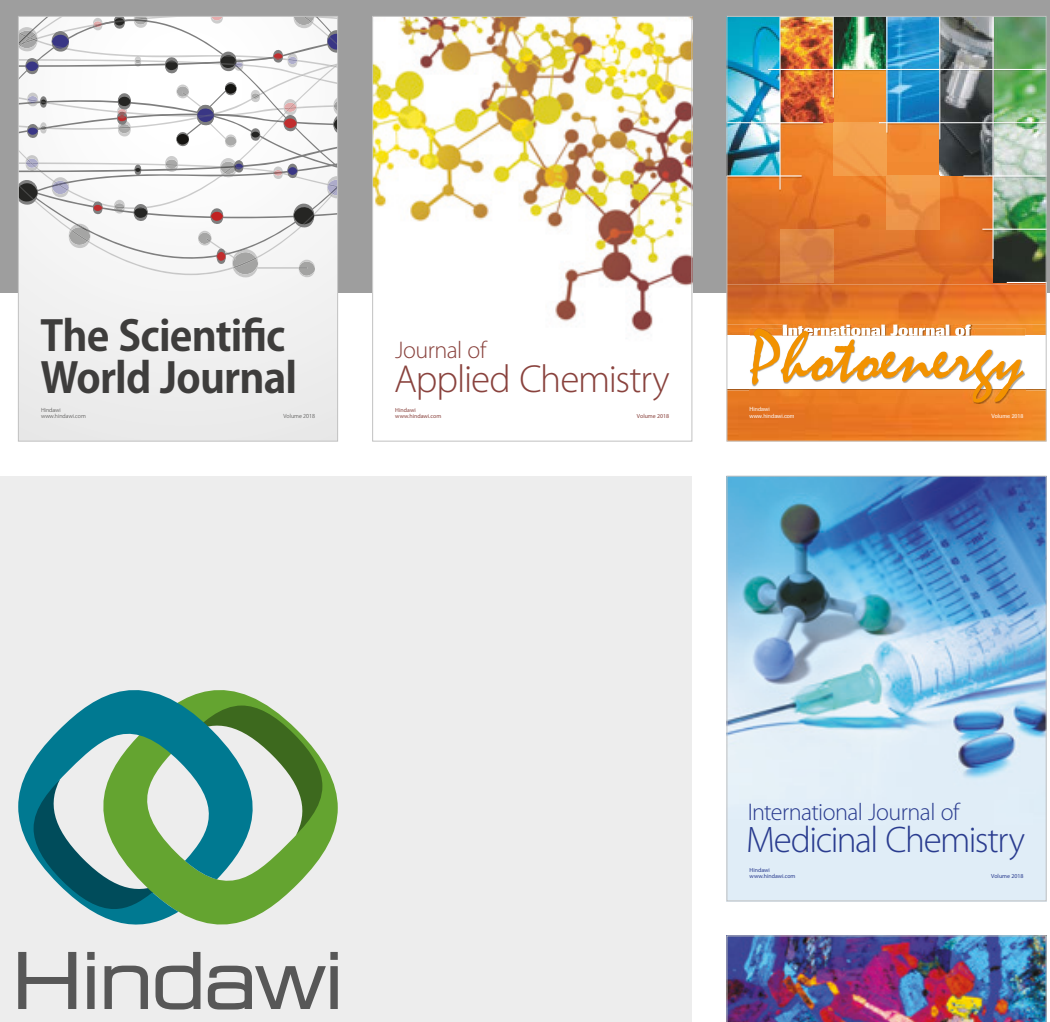

Submit your manuscripts at

www.hindawi.com
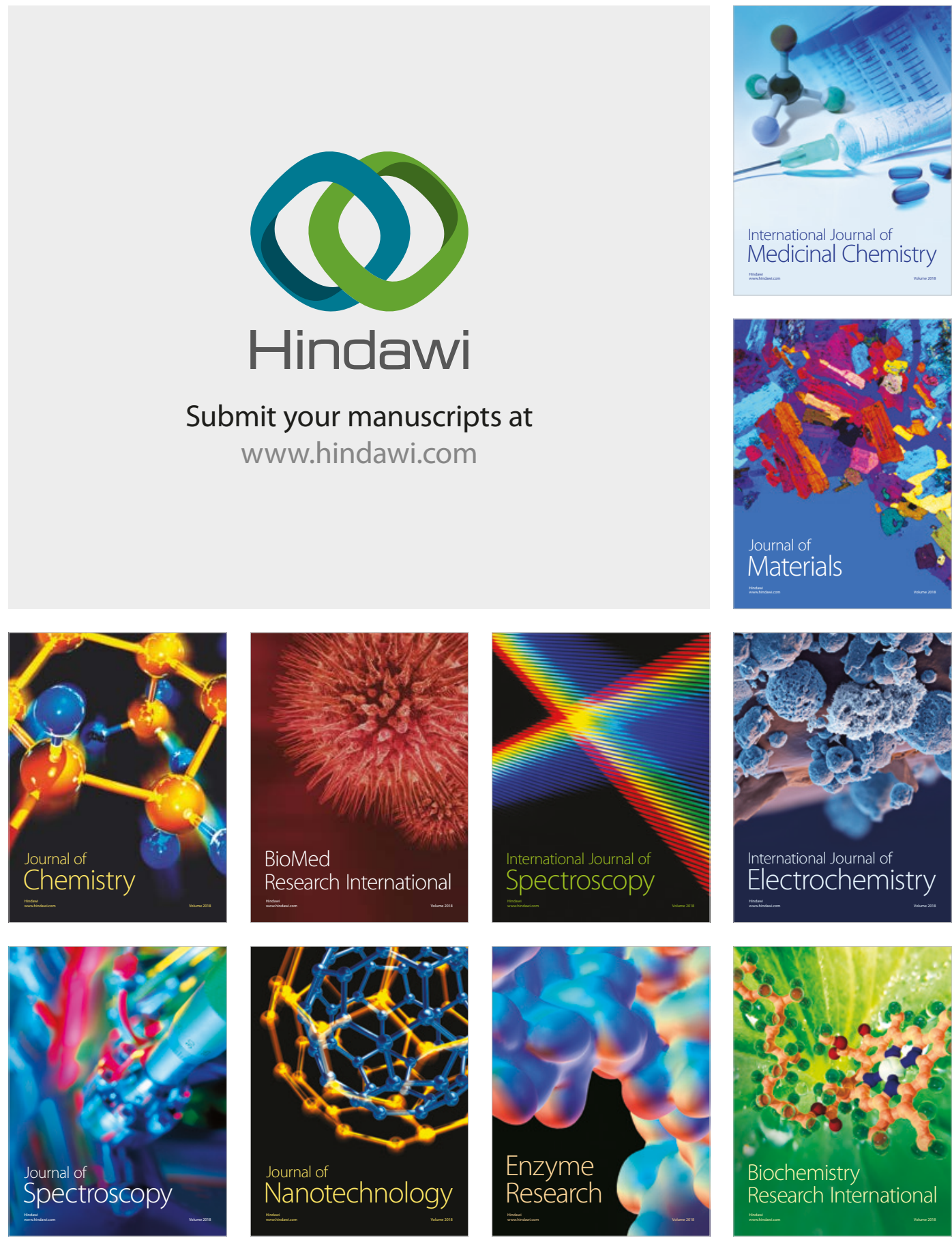
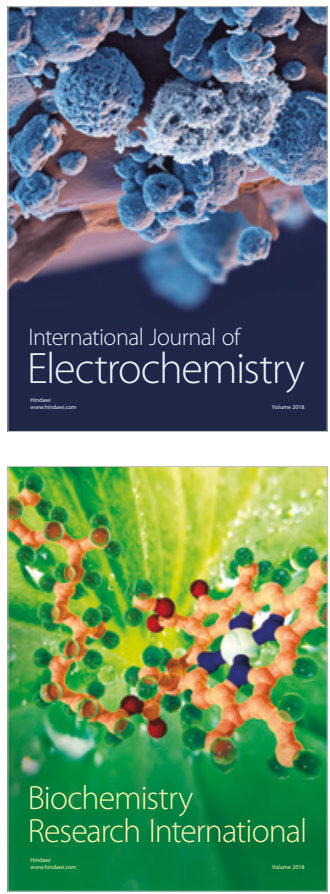